\title{
Optimized Sizing of IPM Machines for Automotive Traction Application
}

\author{
Giorgio Valente $^{1 *}$, David Gerada ${ }^{1 * *}$, Michele Degano $^{1}$, Christopher Gerada $^{1}$ \\ John Foulsham ${ }^{2}$, Daniel Beeby ${ }^{2}$ \\ 1) University of Nottingham, Electrical and Electronic Engineering, Nottingham, United Kingdom \\ 2) GKN, ePowertrain, Abingdon, United Kingdom \\ *ezzgv1@nottingham.ac.uk \\ ** ezadg6@nottingham.ac.uk
}

\begin{abstract}
This paper presents the implementation of an electrical machine design tool including its overall architecture. The tool is flexible and can be employed for the sizing of any permanent magnet synchronous machine. The case study considered in this work is the design of $\mathrm{V}$-shaped interior permanent magnet synchronous machine for automotive applications. The preliminary design stage is considered with the aim of selecting the optimum machine pole pairs number and rotation speed. A multi-objective genetic algorithm is linked to the design tool and adopted to maximize the machine power density in terms of $\mathrm{kW} / \mathrm{L}$ as well as to minimize the machine cost. The outcomes of this work are showing the variation of the above objective functions with respect to the pole-pair number and gearbox ratio as well as their effect on the machine efficiency.
\end{abstract}

Keywords - permanent magnet synchronous machine, high speed electrical machines, automotive, optimization design, genetic algorithm.

\section{INTRODUCTION}

The massive use of fossil fuels has resulted in a dramatic increase of the pollution level over the last few decades leading to the adoption of stringent emissions legislations. The transportation industry is therefore attempting to tackle the aforementioned issues by intensifying the level of electrification in their products. In particular, automotive companies are developing fully electric, hybrid electric and plug-in electric vehicles that would allow improving not only the vehicle emissions and fuel economy but also the performance, passenger comfort and safety [1]. All the power traction solutions for electrical vehicle available in the market make use of ac electrical machines. Among them synchronous permanent magnet machines with embedded rare earth magnets are the most commonly adopted ones [2], [3]. Tesla model $\mathrm{S}$ is an exception as it adopts an induction motor with a copper rotor cage [2].

Performance targets of electrical machines typically depend on the specific application. In the aerospace industry, for instance, the key figure to be maximized is the power to mass ratio $(\mathrm{kW} / \mathrm{kg})$ [4] due to its direct relationship with fuel consumption. On the other hand, the automotive industry is more focused upon maximization of the power to volume ratio $(\mathrm{kW} / \mathrm{L})$ since the available volume in the vehicle is often limited.
Furthermore, aiming at mass production, particular attention is paid on the machine costs, hence the dollar to power ratio $(\$ / \mathrm{kW})$ has to be minimized.

Higher power density can be achieved employing high speed machines. These have found a considerable application uptake in the last couple of decades thanks to the significant development in power electronics switching devices and magnetic materials, capable of withstanding greater mechanical stresses without compromising the iron losses [5].

The tool presented in this paper considers the machine preliminary design stage and allows the designer to identify the most promising machines that meet the requirements with the minimum volume and cost. Indeed, traditional machine sizing would result being too time consuming and impractical due the big number of permutations involved. Therefore, a design tool that rapidly evaluates optimal electrical machines is required for this kind of analysis. The design tool employs a multi-objective Genetic Algorithm to maximize the machine power to volume ratio and minimize the cost.

Optimization techniques have been employed by machine designers since the 1970s, however the GA is one of the most up-to-date and it has been intensively adopted since the end of the 1990s [7],[8],[9]. GA can be considered as an artificial intelligent technique that emulates the mechanism of natural selection and natural genetics. When applied to a motor design, it explores the variables of the design space exploiting mechanisms of reproduction, crossover and mutation in order to produce the optimum design. Several recent papers can be found in the literature which exploits the GA technique to optimize the design in order to improve the machine performances. In reference [11], for instance, the efficiency and power factor maximizations on an induction machine are set as objective of GA. In [12], [13] and [14] the GA targets the minimisation of the torque ripple for PM synchronous machines. These papers only consider the design improvement at the detailed design stage, hence, once the main machine dimensions have already been selected. Reference [4] presents a tool developed for the preliminary design of Surface Mounted Permanent Magnet (SMPM) machines operating at a single power-speed point. The tool is then adopted to select the optimum pole number and rotating speed of the SMPM machine targeting an aerospace 
application where the maximization of the machine $\mathrm{kW} / \mathrm{kg}$ is set as objective in the GA employed.

An automotive application is considered in this paper leading to multiple machine operating points making interior PM (IPM) machines better candidates than the surface mounted ones [10]. Indeed, IPM machines are particularly attractive for automotive because of their wide flux-weakening region, high torque density and efficiency [15]. In particular, they are more compact and present lower inverter capabilities, with respect to induction machines (IMs), when a large Constant Power Speed Ratio (CPSR) is required [15] as, theoretically, the maximum speed can be infinite [16].

\section{DeSign SpeCiFiCATIONS}

a)

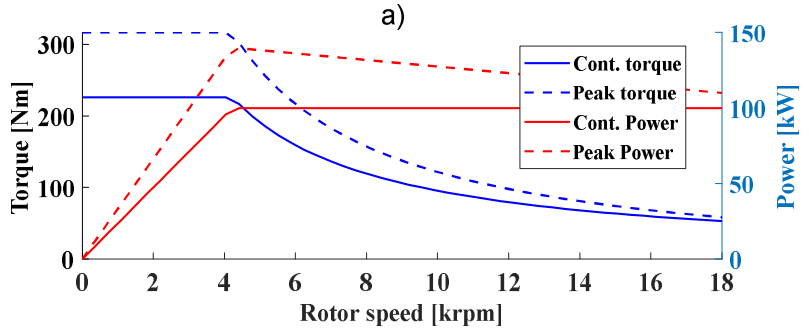

b)

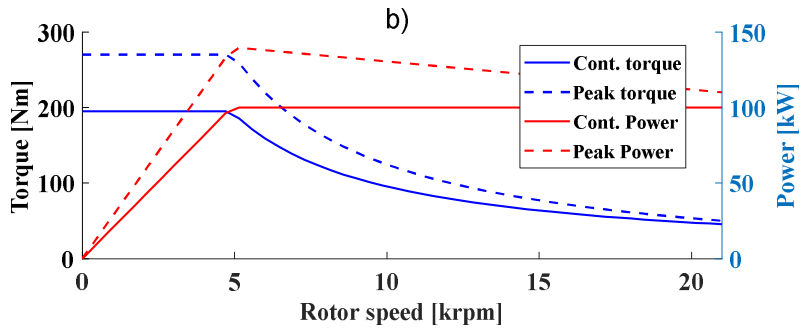

Fig. 2. Speed-torque characteristic: a) gearbox ratio $12: 1$; b) gearbox ratio $14: 1$.

The target vehicle considered in this work is a large SUV with total mass and frontal area equal to $2500 \mathrm{~kg}$ and $3.5 \mathrm{~m}^{2}$, respectively. The required continuous wheel power is $100 \mathrm{~kW}$ in the whole flux-weakening region, while the peak power for short pulses of $60 \mathrm{~s}$ is $140 \mathrm{~kW}$ at the base speed and $110 \mathrm{~kW}$ at the maximum speed. The vehicle has to provide the peak wheel power at the speed of $42 \mathrm{kph}$ that, considering a wheel circumference of $2 \mathrm{~m}$, can be translated into a peak wheel torque of $3800 \mathrm{Nm}$. The vehicle maximum speed is $180 \mathrm{kph}$ leading to a CPSR of 4.3 for the considered machine.

The electrical machine is connected to the wheel through a gearbox. Two different gearbox ratios are considered in this paper: $12: 1$ and 14:1. With the mentioned gearbox ratios, the speed-torque characteristic is computed and reported in Fig. 2 a) and $b$ ) for continuous and peak operating conditions, respectively.

\section{OPERATING PRINCIPLES OF PMSM}

The operating principles of a generic PMSM are presented assuming steady-state operating conditions, neglecting the saturation effects in the iron and adopting the synchronous $d-$ $q$ reference frame with the $d$-axis aligned with the PM polar

a)
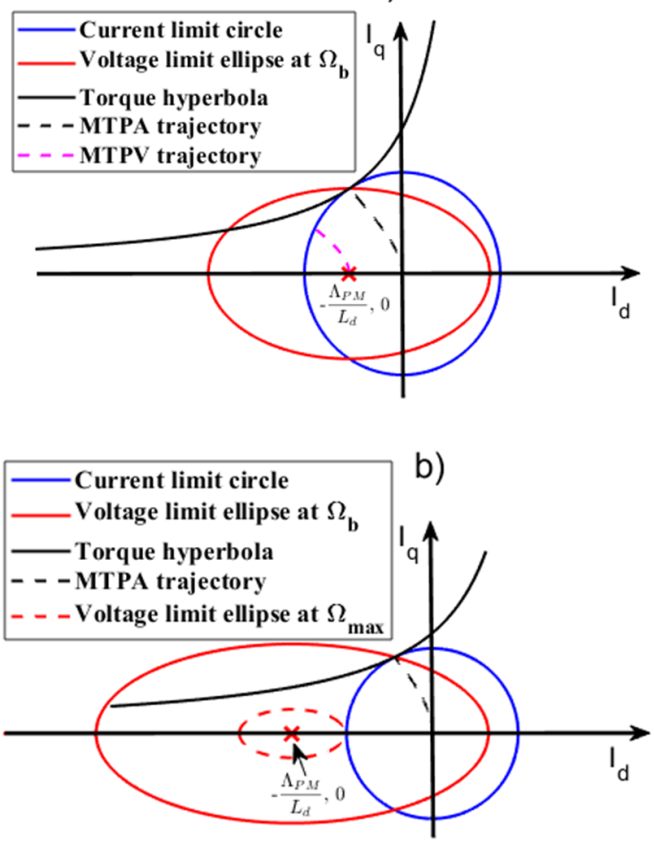

Fig. 1. Circle diagrams in the $I_{d}-I_{q}$ plane: a) $\frac{\Lambda_{P M}}{L_{d}}<I_{N} ; b$ ) $\frac{\Lambda_{\mathrm{PM}}}{\mathrm{L}_{\mathrm{d}}}>\mathrm{I}_{\mathrm{N}}$.

axis.

Considering the above assumptions the steady-state torque T produced by a PMSM can be computed as:

$$
\mathrm{T}=\frac{3}{2} \mathrm{p}\left(\Lambda_{\mathrm{PM}} \mathrm{I}_{\mathrm{q}}+\left(\mathrm{L}_{\mathrm{d}}-\mathrm{L}_{\mathrm{q}}\right) \mathrm{I}_{\mathrm{d}} \mathrm{I}_{\mathrm{q}}\right)
$$

Where $p$ is the machine pole pairs number, $\Lambda_{\mathrm{PM}}$ is the fundamental stator PM flux linkage and $\mathrm{L}_{\mathrm{d}}, \mathrm{L}_{\mathrm{q}}$ and $\mathrm{I}_{\mathrm{d}}, \mathrm{I}_{\mathrm{q}}$ are the $d-q$ axis inductance and current components, respectively. Two torque components can be identified in (1): the PM and reluctance torque components. The PM component is zero for pure reluctance machines $\left(\Lambda_{\mathrm{PM}}=0\right)$ while the reluctance one is zero for SMPM $\left(\mathrm{L}_{\mathrm{d}}=\mathrm{L}_{\mathrm{q}}\right)$. Equation (1) is represented by a hyperbola with asymptotes $\mathrm{I}_{\mathrm{q}}=0$ and $\mathrm{I}_{\mathrm{d}}=-\frac{\Lambda_{\mathrm{PM}}}{\mathrm{L}_{\mathrm{d}}-\mathrm{L}_{\mathrm{q}}}$ in the $\mathrm{I}_{\mathrm{d}}-$ $\mathrm{I}_{\mathrm{q}}$ plane in Fig. 1.

The $\mathrm{d}-\mathrm{q}$ axis current components can be written as a function of the current module I and angle $\gamma$ as in (2).

$$
\begin{aligned}
& I_{d}=I \sin \gamma \\
& I_{q}=I \cos \gamma
\end{aligned}
$$

Being $\mathrm{I}_{\mathrm{N}}$ the rated inverter current, the circle of radius $\mathrm{I}_{\mathrm{N}}$, centered in the origin of the $\mathrm{I}_{\mathrm{d}}-\mathrm{I}_{\mathrm{q}}$ plane defines the inverter current limits. Below the base speed the machine can deliver up to the rated torque choosing $\mathrm{I}_{\mathrm{d}}$ and $\mathrm{I}_{\mathrm{q}}$ in order to achieve Maximum Torque Per Ampere (MTPA). The MTPA locus can be described in the $I_{d}-I_{q}$ plane of Fig. 1 for each current value I by the following equation [16]: 


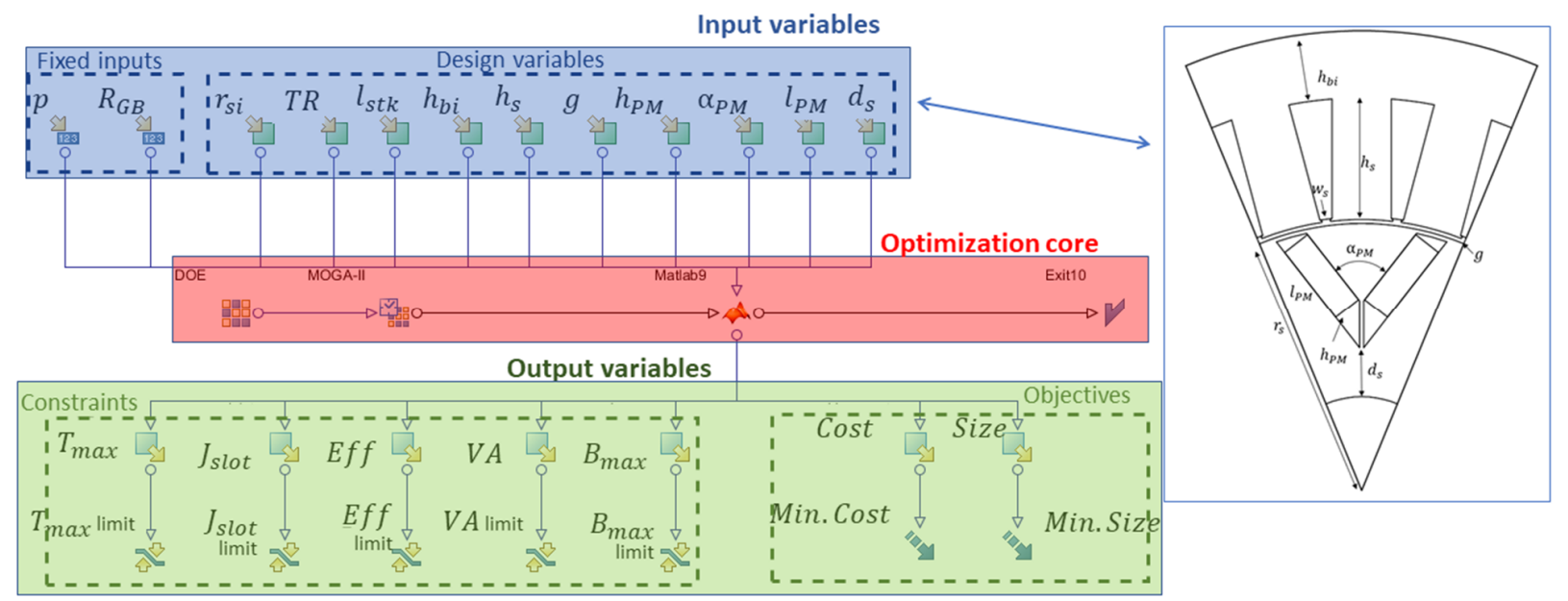

Fig. 3. Diagram of the considered optimization problem implemented in modeFrontier workspace.

$$
\sin \gamma=\frac{\Lambda_{\mathrm{PM}}-\sqrt{\Lambda_{\mathrm{PM}}^{2}+8 \mathrm{I}^{2}\left(\mathrm{~L}_{\mathrm{q}}-\mathrm{L}_{\mathrm{d}}\right)^{2}}}{4\left(\mathrm{~L}_{\mathrm{d}}-\mathrm{L}_{\mathrm{q}}\right) \mathrm{I}}
$$

The $d-q$ axis voltage components can be expressed, neglecting the phase resistance $\mathrm{R}$ [16], as

$$
\begin{gathered}
\mathrm{V}_{\mathrm{d}}=-\Omega_{\mathrm{e}} \mathrm{L}_{\mathrm{q}} \mathrm{I}_{\mathrm{q}} \\
\mathrm{V}_{\mathrm{q}}=\Omega_{\mathrm{e}} \mathrm{L}_{\mathrm{d}} \mathrm{I}_{\mathrm{d}}+\Omega_{\mathrm{e}} \Lambda_{\mathrm{PM}}
\end{gathered}
$$

Where $\Omega_{\mathrm{e}}$ is the electrical angular speed of the machine. Being $\mathrm{V}_{\mathrm{N}}$ the rated inverter voltage, equation

$$
\mathrm{V}_{\mathrm{N}}^{2}=\Omega_{\mathrm{b}}^{2}\left(\left(-\Omega_{\mathrm{b}} \mathrm{L}_{\mathrm{q}} \mathrm{I}_{\mathrm{q}}\right)^{2}+\left(\Omega_{\mathrm{b}} \mathrm{L}_{\mathrm{d}} \mathrm{I}_{\mathrm{d}}+\Omega_{\mathrm{b}} \Lambda_{\mathrm{PM}}\right)^{2}\right)
$$

where $\Omega_{\mathrm{b}}$ is the machine base speed, describes an ellipse in the $I_{d}-I_{q}$ plane that defines the inverter voltage limits. The ellipse is centred in $\left(-\frac{\Lambda_{\mathrm{PM}}}{\mathrm{L}_{\mathrm{d}}}, 0\right)$ and has the major axis and ellipticity equal to $\frac{2 V_{N}}{\Omega_{b} L_{d}}$ and $\frac{L_{q}}{L_{d}}$, respectively. The ellipse centre represents the steady state three-phase short circuit current. The latter can be smaller or greater than the $\mathrm{I}_{\mathrm{N}}$ depending on the values of $\Lambda_{\mathrm{PM}}$ and $\mathrm{L}_{\mathrm{d}}$ as shown in Fig. 1 a) and b), respectively.

Above the base speed the machine operates in the fluxweakening region, or constant volt-ampere region. The operating points can be identified in the $\mathrm{I}_{\mathrm{d}}-\mathrm{I}_{\mathrm{q}}$ plane of Fig. 1 as the intersection of the voltage limit ellipse (with $\Omega_{\mathrm{e}}>\Omega_{\mathrm{b}}$ ) with the current limit circle. Depending then whether the ellipse centre lies outside or inside the current limit circle the machine speed can be limited to

$$
\Omega_{\text {max }}=\frac{\mathrm{V}_{\mathrm{N}}}{\Lambda_{\mathrm{PM}}-\mathrm{L}_{\mathrm{d}} \mathrm{I}_{\mathrm{N}}}
$$

or unlimited [16]. The first case is depicted in Fig. $1 \mathrm{~b}$ ) with the voltage limit at $\Omega_{\max }$ represented the dashed red ellipse and the machine operating in the flux-weakening region up to the maximum speed. In the second case instead, the machine speed is theoretically infinite $\left(\Omega_{\max }=\infty\right)$ and operating limits are defined by the Maximum Torque Per Voltage (MTPV) locus as shown in Fig. 1 b) by the dashed magenta line. In this region, the relationship between $d$-axis and $q$-axis currents is expressed in (7).

$$
\mathrm{I}_{\mathrm{q}}=\frac{\mathrm{L}_{\mathrm{d}}}{\mathrm{L}_{\mathrm{q}}} \sqrt{\frac{-\left(\mathrm{I}_{\mathrm{d}}+\frac{\Lambda_{\mathrm{PM}}}{\mathrm{L}_{\mathrm{d}}}\right)\left(\Lambda_{\mathrm{PM}}+\left(\mathrm{L}_{\mathrm{q}}-\mathrm{L}_{\mathrm{d}}\right) \mathrm{I}_{\mathrm{d}}\right)}{\mathrm{L}_{\mathrm{q}}-\mathrm{L}_{\mathrm{d}}}}
$$

\section{PMSM DESIGN TOOL}

A. GA-based platform

Table I

\begin{tabular}{cc}
\hline & GEOMETRICAL PARAMETERS \\
\hline \hline Name & Description \\
\hline $\mathrm{r}_{\mathrm{si}}$ & Inner stator radius \\
$\mathrm{TR}$ & Slot width to tooth width ratio \\
$\mathrm{l}_{\mathrm{stk}}$ & Stack length \\
$\mathrm{h}_{\mathrm{bi}}$ & Back-Iron height \\
$\mathrm{h}_{\mathrm{s}}$ & Slot height \\
$\mathrm{g}$ & Airgap length \\
$\mathrm{h}_{\mathrm{PM}}$ & PM height \\
$\alpha_{\mathrm{PM}}$ & Angle between two PMs \\
$\mathrm{d}_{\mathrm{s}}$ & Distance of the V slot from shaft \\
$\mathrm{l}_{\mathrm{PM}}$ & PM length
\end{tabular}

The sizing tool developed is based on a commercial optimization software, modeFrontier [17], where the optimization problem is defined. Fig. 3 shows the diagram taken from modeFrontier workspace. The diagram can be divided into three parts: input variables, optimization core and output constraints/objectives. The design variables represent all the machine geometrical parameters considered in the optimization problem. The geometrical parameters considered to size a Vshaped IPM machine are listed in Table I. These are the inputs of the Matlab design environment located together with the Design Of Experiment (DOE) and MOGA-II blocks in the optimization core. The DOE creates the initial population, based on a pseudo-random sequence defined by the user (typically set to around 300), while in MOGA-II the optimization routine is selected. The Matlab block instead, links modeFrontier with a 
a)

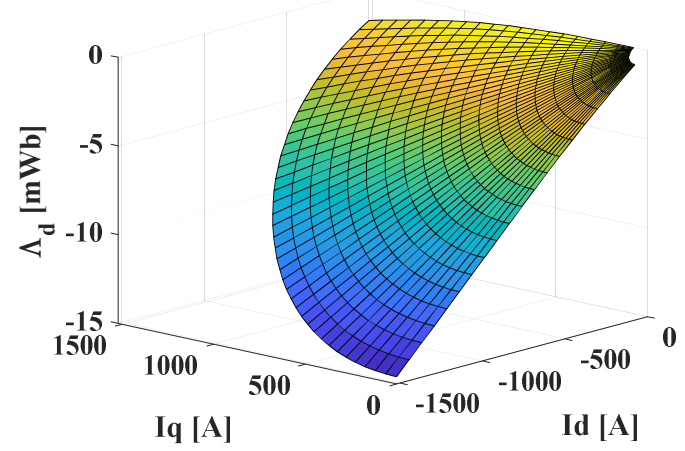

b)

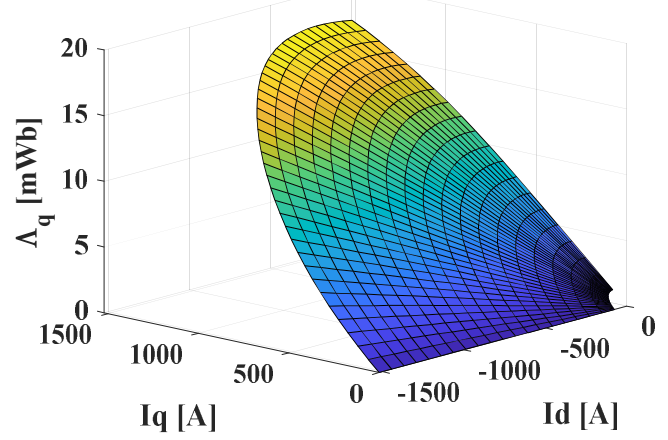

Fig. 4. $d-q$ axis flux maps as a function of $\mathrm{I}_{\mathrm{d}}$ and $\mathrm{I}_{\mathrm{q}}$ : a) d-axis flux map; b) q-axis flux map.

Matlab script that acts as multi-domain evaluation calculator where all the output variables are computed. In the next paragraph the Matlab calculator will be described in details. The output constraints and objectives can be found in the bottom part of the schematic. Given the considered automotive application the key figures to be optimized are the machine $\mathrm{kW} / \mathrm{L}$ and $\$ / \mathrm{kW}$. Therefore, the machine size and cost, output of the Matlab block, are defined as objective functions to be minimized. The output constraints include the winding temperature $T_{\max }$, the current density $J_{\text {slot }}$, the machine efficiency, the flux density in the stator teeth and back-iron $B_{\max }$, as well as the machine voltsampere rating $V A$. The latter depends on the DC-link voltage level $V_{D C}$ and current rating $\mathrm{I}_{\mathrm{N}}$ of the inverter power module. Then, the maximum available $V A$ can be calculated as in (8).

$$
V A=\frac{3}{2} \frac{V_{D C}}{\sqrt{3}} \mathrm{I}_{\mathrm{N}}
$$

Finally, in the top left part of the schematic the pole pairs number $\mathrm{p}$ and the gearbox ratio $\mathrm{R}_{\mathrm{GB}}$ are defined as fixed input parameters allowing the user to seek the optimum machine in a wide search space.

\section{B. Matlab calculator}

The Matlab calculator script receives the inputs from modeFrontier and computes the outputs. The case study machine considered in this work is a V-shaped IPM machine as the one shown in the top right corner of Fig. 3. At first, the cost and size of the different machine active parts can be readily obtained knowing the material properties and the geometrical parameters listed in Table I. The cost of the different materials has been calculated assuming a unit cost of $10 \$ / \mathrm{kg}$ for the lamination, $15 \$ / \mathrm{kg}$ for the winding and $150 \$ / \mathrm{kg}$ for the PM. Then, the geometrical parameters are used to draw one machine pole in the FE software MagNet 7.8.3 where the boundary conditions are imposed. Indeed, exploiting the geometrical symmetries of the machine only one pole can be considered for the analysis markedly reducing the computation time. Machines with a number of slots per pole per phase $q=1$ are considered in this paper. Furthermore, random strand wire is employed leading to a slot fill factor $\mathrm{k}_{\mathrm{fill}}=0.5$. The machine analysis is achieved at this preliminary design stage assuming one turn per pole per phase. The number of turns can then be adjusted considering the available DC-link voltage $V_{D C}$ in a later detailed design stage. Neodymium iron boron with residual flux density $\mathrm{B}_{\mathrm{r}} @ 20 \operatorname{deg} \mathrm{C}=1.08 \mathrm{~T}$ and copper are selected as $\mathrm{PM}$ and winding materials, respectively. High strength thin non-oriented silicon steel is adopted for the rotor laminations. For the initial sizing, the peripheral speed is constrained to limit the centrifugal stresses, with more detailed mechanical analysis subsequently performed. Therefore, the rotor outer radius is limited by the expression

$$
r_{\text {rot }}<\frac{30}{\pi} \frac{\mathrm{v}_{\mathrm{p}}}{\mathrm{v}_{\mathrm{rpm}}}
$$

Where $\mathrm{v}_{\text {rpm }}$ is the maximum rotating speed in rpm, equal to $\mathrm{v}_{\mathrm{rpm}}=18 \mathrm{krpm}$ and $\mathrm{v}_{\mathrm{rpm}}=21 \mathrm{krpm}$ for the $12: 1$ and $14: 1$ gearbox ratios, respectively. The peripheral speed has to be limited to $v_{p}=150 \mathrm{~m} / \mathrm{s}$ for the rotor lamination grade chosen, leading to a maximum rotor radius $r_{\text {rot }}=79.6 \mathrm{~mm}$ and $r_{\text {rot }}=$ $68.2 \mathrm{~mm}$ for the two considered gearbox ratios.

Once the model is completed, the machine can be analyzed through computationally efficient FEA simulations. At first, a no-load static simulation is performed and the fundamental stator PM flux linkage $\Lambda_{\mathrm{PM}}$ is computed. Then, the machine is analysed at different operating points in order to compute the required quantities such as current density in the slots $J_{\text {slot }}$, maximum flux density in the teeth and back-iron $\mathrm{B}_{\max }$, efficiency and volts-ampere rating. Calculating the mentioned quantities at different operating points requires accurate maps of the $d-q$ axis flux linkages $\Lambda_{\mathrm{d}}$ and $\Lambda_{\mathrm{q}}$ that consider the saturation and cross-coupling effects [18]. The machine $d-q$ axis inductances can then be calculated as

$$
\begin{aligned}
& \mathrm{L}_{\mathrm{d}}\left(\mathrm{I}_{\mathrm{d}}, \mathrm{I}_{\mathrm{q}}\right)=\frac{\Lambda_{\mathrm{d}}\left(\mathrm{I}_{\mathrm{d}}, \mathrm{I}_{\mathrm{q}}\right)}{\mathrm{I}_{\mathrm{d}}} \\
& \mathrm{L}_{\mathrm{q}}\left(\mathrm{I}_{\mathrm{q}}, \mathrm{I}_{\mathrm{d}}\right)=\frac{\Lambda_{\mathrm{q}}\left(\mathrm{I}_{\mathrm{q}}, \mathrm{I}_{\mathrm{d}}\right)}{\mathrm{I}_{\mathrm{q}}}
\end{aligned}
$$

Therefore, an analytical expression of $\Lambda_{d}\left(I_{d}, I_{q}\right)$ and $\Lambda_{q}\left(I_{q}, I_{d}\right)$ is required. The procedure to obtain the expression of $\Lambda_{d}\left(I_{d}, I_{q}\right)$ and $\Lambda_{\mathrm{q}}\left(\mathrm{I}_{\mathrm{q}}, \mathrm{I}_{\mathrm{d}}\right)$ required in (10) is reported as follow. At first a map of $\Lambda_{d}\left(I_{d}, I_{q}\right)$ and $\Lambda_{q}\left(I_{q}, I_{d}\right)$ is computed running different FE simulations varying the current module I and angle $\gamma$ from 0 


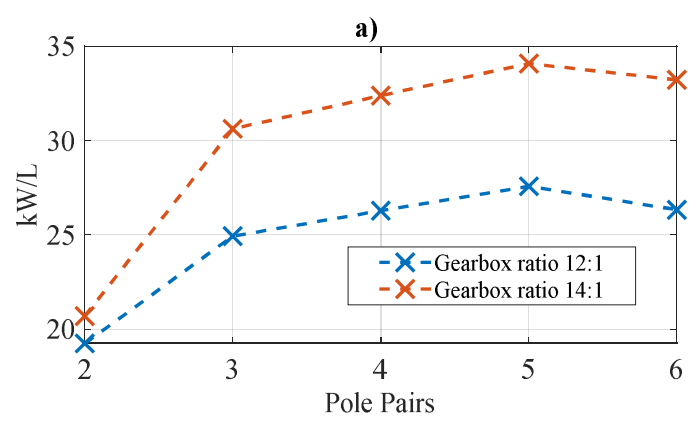

b)
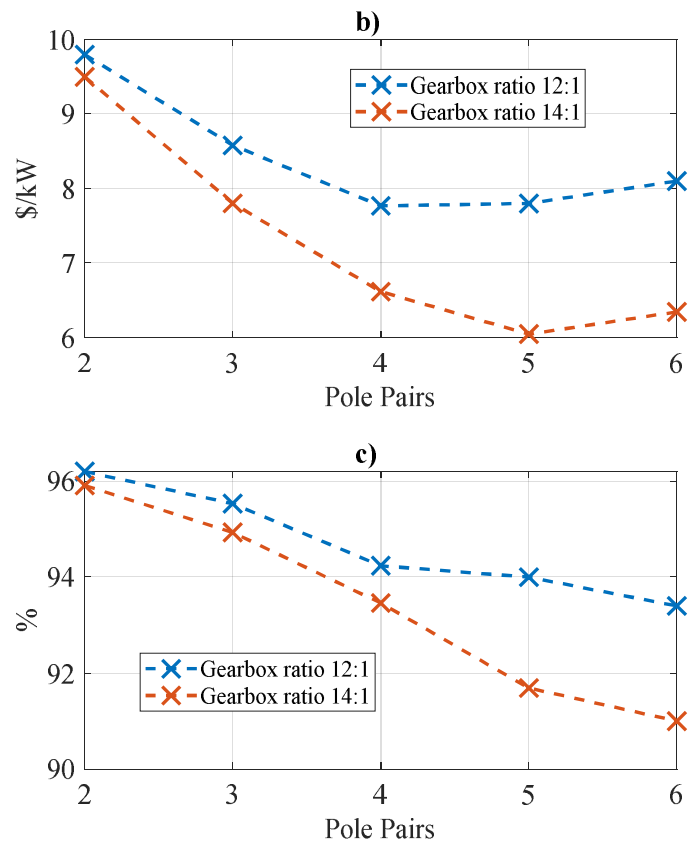

Fig. 5. Generated charts: a) $\mathrm{kW} / \mathrm{L}$ vs pole pairs; b) $\$ / \mathrm{kW}$ vs pole pairs; c) Efficiency vs pole pairs.

to the rated current and from 0 to 90 electrical deg, respectively. An example of $\Lambda_{d}\left(I_{d}, I_{q}\right)$ and $\Lambda_{q}\left(I_{q}, I_{d}\right)$ maps is displayed in Fig. 4 a) and b) respectively for a 4-pole $V$-shaped machine. The maps shown in the figure are obtained with 20 values of the current module I and 40 values of the current angle $\gamma$. Once the flux maps are obtained, polynomial expressions of the $\Lambda_{d}$ and $\Lambda_{\mathrm{q}}$ as a function of both $d-q$ axis current components can be obtained in form of equations (11) and (12), respectively.

$$
\begin{gathered}
\Lambda_{d}\left(I_{d}, I_{q}\right)=a_{d 1} I_{d}^{2}+a_{d 2} I_{d}+a_{d 3} I_{q}^{2}+a_{d 4} I_{q} \\
+a_{d 5} I_{d} I_{q}+a_{d 6} \\
\Lambda_{q}\left(I_{d}, I_{q}\right)=a_{q 1} I_{d}^{2}+a_{q 2} I_{d}+a_{q 3} I_{q}^{2}+a_{q 4} I_{q} \\
+a_{q 5} I_{d} I_{q}+a_{\mathrm{q} 6}
\end{gathered}
$$

The polynomial coefficients in (11) and (12) can be obtained with the Matlab function " $f i t$ ". In order to reduce the computational time, 3 values of the current module I and 5 values of the current angle $\gamma$ are used to calculate the $d-q$ axis flux maps.

Once the $d-q$ axis inductances are obtained as in (10), the machine can be analyzed in the entire speed-torque characteristic applying the equations presented in Section III. In particular, for operating points up to the base speed $\Omega_{\mathrm{b}}$ the $d-$ $q$ axis machine currents are computed solving the system of equations (1), (2) and (3). On the other hand, when $\Omega_{\mathrm{e}}>\Omega_{\mathrm{b}}$ the machine operates in the flux-weakening region and then in the MPTV region if $\frac{\Lambda_{\mathrm{PM}}}{\mathrm{L}_{\mathrm{d}}}<\mathrm{I}_{\mathrm{N}}$. Above $\Omega_{\mathrm{b}}$ the voltage has to be limited to $\mathrm{V}_{\mathrm{N}}$, hence the $d-q$ axis voltage components have to be calculated as in (4) and the following inequality has to be verified.

$$
\sqrt{\mathrm{V}_{\mathrm{d}, \mathrm{fw}}^{2}+\mathrm{V}_{\mathrm{q}, \mathrm{fw}}^{2}} \leq \mathrm{V}_{\mathrm{N}}
$$

Where $\mathrm{V}_{\mathrm{d}, \mathrm{fw}}$ and $\mathrm{V}_{\mathrm{q}, \mathrm{fw}}$ are the $d-q$ axis voltage components in the flux-weakening region.

The thermal analysis of electrical machine is of fundamental importance to verify that the different machine components do not overheat. For the high power density applications, such as the considered traction motor, conventional cooling methods may not be sufficient to achieve the ambitious next generation motor performance targets. Therefore, the cooling method selected for this work is a combination of housing water jacket and oil-spray cooling of the end-winding with coolant phase change [19]. A lumped parameter thermal model has been implemented in the Matlab script. The model allows calculating the temperature in the machine hotspots in order to limit their values by means the constraint implemented in modeFrontier.

\section{RESUlts}

This section presents the optimization results obtained with the proposed design tool. The pole pairs number goes from 2 to 6. The two previously mentioned gearbox ratios will be evaluated with the aim of finding the best combination of gearbox ratio and pole pairs number for the considered application.

Fig. 5 shows the generated charts with the objective functions: kW/L vs pole pairs number in Fig. 5 a), $\$ / \mathrm{kW}$ vs pole pairs number in Fig. 5 b) and efficiency vs pole pairs number in Fig. 5 c). Both the trends for gearbox ratios 12:1 and 14:1 are displayed in the figure. The trends suggest that, for both gearbox ratios, increasing the pole pairs number reduces the size and cost of the machine. However, it can be noticed from Fig. 5 c) that the efficiency significantly decreases with the pole pairs number. The most frequent machine operating point within a drive cycle, based on residence analysis, has been considered for the efficiency calculation. It can be then noticed from the figure that the machines designed for a smaller gearbox ratio, hence lower rotating speed, are bigger and more expensive but they feature a higher efficiency, especially for high pole pairs numbers. Therefore, the choice of the pole pairs number and gearbox ratio will be a trade-off between high efficiency and compact and cheap machines and it has to be done at a systemlevel.

The PC used to run the optimizations has a Quad Intel Xeon 3.5 GHz CPU and $32 \mathrm{~GB}$ of installed RAM. The computation time required to draw one random machine and perform the FEA explained in Section IV.B is around $30 \mathrm{~s}$. The solution of one optimization problem with a given set of inputs (pole pairs 
number and gear box ratio) where thousands of machines are evaluated takes between 25 and 30 hours. Therefore, to generate the chart considered with 5 optimized machine designs took around 120 hours.

\section{CONCLUSIONS}

A GA-based PMSM sizing tool has been proposed in this paper. The methodology and main elements of the tool have been presented together with of the description of the calculator core. The tool has been employed to design a $\mathrm{V}$-shaped machine for an automotive application where it is required to minimize the size and cost. However, its flexibility allows to consider any PMSM and any constraint and objective function can be set in the optimization problem depending on the applications requirements allowing the system designer to take the best system-level decision, such as the selection of optimal gearing ratio and optimal transmission-motor combination.

For the considered case study it has been shown that high $\mathrm{kW} / \mathrm{L}$ and low $\$ / \mathrm{kW}$ levels can be achieved with advanced cooling with a high pole-pair number and a high gearbox ratio paying the price of reducing the machine efficiency.

\section{ACKNOWLEDGMENT}

The authors would like to thank GKN ePowertrain for their continued support with traction motor research.

\section{REFERENCES}

[1] A. Emadi, Y. J. Lee and K. Rajashekara, "Power Electronics and Motor Drives in Electric, Hybrid Electric, and Plug-In Hybrid Electric Vehicles," in IEEE Transactions on Industrial Electronics, vol. 55, no. 6, pp. 22372245, June 2008.

[2] M. Popescu, J. Goss, D. A. Staton, D. Hawkins, Y. C. Chong and A. Boglietti, "Electrical Vehicles-Practical Solutions for Power Traction Motor Systems," in IEEE Transactions on Industry Applications, vol. 54 no. 3, pp. 2751-2762, May-June 2018.

[3] Y. Sato et al., "Development of high response motor and inverter system for the Nissan LEAF electric vehicle", Proc. Int. World Congr. Exhib., Apr. 2011

[4] D. Golovanov, L. Papini, D. Gerada, Z. Xu and C. Gerada, "Multidomain Optimization of High-Power-Density PM Electrical Machines for System Architecture Selection," in IEEE Transactions on Industrial Electronics, vol. 65 , no. 7 , pp. 5302-5312, July 2018.

[5] D. Gerada, A. Mebarki, N. L. Brown, C. Gerada, A. Cavagnino, A. Boglietti, "High speed electrical machines-Technologies trends and developments", IEEE Trans. Ind. Electron., vol. 61, no. 6, pp. 2946-2959, Jun. 2014.
[6] R. Ramarathnam, B. G. Desai and V. S. Rao, "A Comparative Study of Minimization Techniques for Optimization of Induction Motor Design," in IEEE Transactions on Power Apparatus and Systems, vol. PAS-92, no. 5, pp. 1448-1454, Sept. 1973.

[7] S. Palko and T. Jokinen, "Optimisation of squirrel cage induction motors using finite element method and genetic algorithms," 1997 Eighth International Conference on Electrical Machines and Drives (Conf. Publ. No. 444), Cambridge, UK, 1997, pp. 21-25.

[8] N. Bianchi and S. Bolognani, "Design optimisation of electric motors by genetic algorithms," in IEE Proceedings - Electric Power Applications, vol. 145 , no. 5 , pp. 475-483, Sept. 1998.

[9] Dong-Hyeok Cho, Hyun-Kyo Jung and Cheol-Gyun Lee, "Induction motor design for electric vehicle using a niching genetic algorithm," IEEE International Electric Machines and Drives Conference. IEMDC'99. Proceedings (Cat. No.99EX272), Seattle, WA, USA, 1999, pp. 290-292.

[10] A. Vagati, G. Pellegrino and P. Guglielmi, "Comparison between SPM and IPM motor drives for EV application," The XIX International Conference on Electrical Machines - ICEM 2010, Rome, 2010, pp. 1-6.

[11] T. György and K. A. Biró, "Genetic Algorithm based design optimization of a three-phase induction machine with external rotor," 2015 Intl Aegean Conference on Electrical Machines \& Power Electronics (ACEMP), 2015 Intl Conference on Optimization of Electrical \& Electronic Equipment (OPTIM) \& 2015 Intl Symposium on Advanced Electromechanical Motion Systems (ELECTROMOTION), Side, 2015, pp. 462-467.

[12] M. Degano, E. Carraro and N. Bianchi, "Selection Criteria and Robust Optimization of a Traction PM-Assisted Synchronous Reluctance Motor," in IEEE Transactions on Industry Applications, vol. 51, no. 6, pp. 43834391, Nov.-Dec. 2015.

[13] C. Lai, G. Feng, K. L. V. Iyer, K. Mukherjee and N. C. Kar, "Genetic Algorithm-Based Current Optimization for Torque Ripple Reduction of Interior PMSMs," in IEEE Transactions on Industry Applications, vol. 53, no. 5, pp. 4493-4503, Sept.-Oct. 2017.

[14] W. Zhao, J. Kwon, X. Wang, T. A. Lipo and B. Kwon, "Optimal Design of a Spoke-type Permanent Magnet Motor with Phase-group Concentrated-coil Windings to Minimize Torque Pulsations," in IEEE Transactions on Magnetics, vol. 53, no. 6, pp. 1-4, June 2017.

[15] G. Pellegrino, A. Vagati and P. Guglielmi, "Design Tradeoffs Between Constant Power Speed Range, Uncontrolled Generator Operation, and Rated Current of IPM Motor Drives," in IEEE Transactions on Industry Applications, vol. 47, no. 5, pp. 1995-2003, Sept.-Oct. 2011.

[16] N. Bianchi and S. Bolognani, "Parameters and volt-ampere ratings of a synchronous motor drive for flux-weakening applications," in IEEE Transactions on Power Electronics, vol. 12, no. 5, pp. 895-903, Sept. 1997.

[17] Clarich, Alberto, R. Russo, and M. Carriglio. "Multi-objective optimization with modefrontier interfaces for ansa and metapost." 4th ANSA \& $\mu$ ETA International Conference. Thessaloniki, Greece. 2011.

[18] M. H. Mohammadi and D. A. Lowther, "A computational study of efficiency map calculation for synchronous AC motor drives including cross coupling and saturation effects," 2016 IEEE Conference on Electromagnetic Field Computation (CEFC), Miami, FL, 2016, pp. 1-1.

[19] Y. Gai et al., "Cooling of Automotive Traction Motors: Schemes, Examples, and Computation Methods," in IEEE Transactions on Industrial Electronics, vol. 66, no. 3, pp. 1681-1692, March 2019. 